\title{
Response of the North Atlantic storm track to climate change shaped by ocean- atmosphere coupling
}

Article

Accepted Version

Woollings, T., Gregory, J. M., Pinto, J. G., Reyers, M. and Brayshaw, D. J. (2012) Response of the North Atlantic storm track to climate change shaped by ocean-atmosphere coupling. Nature Geoscience, 5 (5). pp. 313-317. ISSN 17520894 doi: https://doi.org/10.1038/ngeo1438 Available at https://centaur.reading.ac.uk/28408/

It is advisable to refer to the publisher's version if you intend to cite from the work. See Guidance on citing.

To link to this article DOI: http://dx.doi.org/10.1038/ngeo1438

Publisher: Nature Publishing Group

All outputs in CentAUR are protected by Intellectual Property Rights law, including copyright law. Copyright and IPR is retained by the creators or other copyright holders. Terms and conditions for use of this material are defined in the End User Agreement.

www.reading.ac.uk/centaur 
Central Archive at the University of Reading

Reading's research outputs online 
1. Response of the North Atlantic storm track to

2. climate change shaped by ocean-atmosphere coupling

Department of Meteorology, University of Reading, Earley Gate, PO Box 243, Reading, RG6 6BB, UK.

*Corresponding author email: t.j.woollings@reading.ac.uk

5

NCAS-Climate, Department of Meteorology, University of Reading and Met Office Hadley Centre, Exeter, UK.

6

Institute for Geophysics and Meteorology, University of Cologne, Kerpener St. 13, Cologne, Germany.

\section{,}

Department of Meteorology and NCAS-Climate, University of Reading, Earley Gate, PO Box 243, Reading, RG6 6BB, UK. 
A poleward shift of the mid-latitude storm tracks in response to anthropogenic greenhouse-gas forcing has been diagnosed in climate model simulations ${ }^{1 ; 2}$. Explanations of this effect have focused on atmospheric dynamics ${ }^{3 ; 4 ; 5 ; 6 ; 7}$. However, in contrast to storm tracks in other regions, the North Atlantic storm track responds by strengthening and extending further east, in particular on its southern flank ${ }^{8}$. These adjustments are associated with an intensification and extension of the eddy-driven jet towards western Europe ${ }^{9}$ and are expected to have considerable societal impacts related to a rise storminess in Europe ${ }^{10 ; 11 ; 12}$. Here we apply a regression analysis to an ensemble of coupled climate model simulations to show that the coupling between ocean and atmosphere shapes the distinct storm track response to greenhouse-gas forcing in the North Atlantic region. In the ensemble of simulations we analyse, at least half of the difference between the storm track responses of different models is associated with uncertainties in ocean circulation changes. We compare the fully coupled simulations with both the associated slab model simulations and an ocean-forced experiment with one climate model to establish causality. We conclude that uncertainties in the response of the North Atlantic storm track to anthropogenic emissions could be reduced through tighter constraints on the future ocean circulation.

We focus on the role of the Meridional Overturning Circulation (MOC) which transports heat northwards in the Atlantic Ocean. There is evidence from modelling studies that the MOC has an influence on both the mean state ${ }^{13 ; 14 ; 15}$ and variability ${ }^{16}$ of the storm track. The MOC is projected to weaken in response to greenhouse-gas forcing ${ }^{1}$ and over the northern North Atlantic this is expected to offset some of the greenhouse-induced warming in sea surface temperature (SST). 
The meridional gradient in SST is therefore projected to increase in the midlatitude North Atlantic, implying an increase in the baroclinic instability from which the storm track draws its energy. Some studies have speculated that the storm track and MOC/SST responses might be related ${ }^{17 ; 18 ; 19 ; 20}$ but this has never been investigated specifically. Here we show that the MOC is an important factor influencing both the mean storm track response of climate models and the spread between different models (using the CMIP3 models; see methods for more details).

We begin by comparing the MOC reduction in each model with the surface temperature response to the forcing. To do this we calculate the temperature response pattern (2060-99 - 1960-99) for each model and regress this set of patterns on a vector comprising the MOC reduction in the same models between the same two periods. The result is given in Figure 1a, showing that a larger MOC reduction is associated with a greater cooling in the North Atlantic, which locally offsets the greenhouse warming. This is consistent with the role of the MOC in transporting heat northward into this region. A dimensional version of this regression analysis applied to the region $\left(20-60^{\circ} \mathrm{W}, 45-70^{\circ} \mathrm{N}\right)$ gives a temperature change of $0.31 \mathrm{~K}$ for a $1 \mathrm{~Sv}$ weakening of the MOC, consistent with previous analyses ${ }^{21 ; 22}$, with a corresponding correlation of 0.67 .

Figure 1c shows the regression of the storm track response onto the MOC response (see Methods). This shows a clear and significant signal, with models featuring a strong $\mathrm{MOC}$ response also exhibiting a particular strengthening and eastward extension of the storm track towards Europe. The regression of $850 \mathrm{hPa}$ zonal wind responses onto the MOC responses is shown in Figure 1b, indicating a strengthening and eastward extension of the low-level westerlies over and downstream of the main storm track region, consistent with the mean flow forcing expected from a strengthening of the storm track. If the regression is instead performed on the global mean temperature response of the models there are no 
significant regressions for either of the atmospheric fields (not shown). This shows that while the Atlantic storm track response is related to the weakening of the MOC, it has no dependence on the climate sensitivity of the models.

In comparing the storm track response to the MOC response the set of models is reduced significantly due to data availability. To demonstrate that a similar relation is likely seen across all the models we show a similar analysis in Figure 1de using only the atmospheric fields. We take the leading Empirical Orthogonal Function (EOF) of the set of surface temperature response patterns as a proxy for the MOC response in the full set of climate models. In this application, the EOFs are the patterns which explain most of the spread between the 22 individual model response patterns, and the principal components give the relative projection of each model response pattern onto the corresponding EOF. The leading EOF over this North Atlantic region (Figure 1d) is very similar to the surface temperature regression onto the MOC response, which implies that the MOC plays a leading role in the spread in North Atlantic temperature response. The regressions of zonal wind and storm track activity onto the associated principal component are shown in Figure 1e-f. The storm track response in particular is also very similar to its counterpart in the MOC analysis, suggesting that the MOC-storm track relation carries over to the full set of models. The wind patterns show some difference in the mid-Atlantic but are again quite similar over Europe where the pattern in Figure 1e is most significant.

To show that these relationships are consistent with the influence of the MOC on the storm track we show in Figure 1g-i the results of a freshwater hosing experiment with the HadCM3 climate model. In this experiment the MOC was artificially shut down by continuously adding fresh water to the North Atlantic ${ }^{23}$. The responses shown here comprise the differences between twenty year equilibrium periods in the hosing and control runs ${ }^{13}$ and have been linearly scaled so that 
the patterns correspond to the same MOC change as in panels a-c (3.5Sv). The response to MOC shutdown is very similar to the regressions among the CMIP3 models, with surface cooling in the northern North Atlantic and a strengthening and extension of the storm track and zonal wind downstream into Europe. This quantitative comparison suggests that the MOC changes seen in the CMIP3 models are able to cause storm track changes at least as large as those seen. Some differences from the regression patterns are evident, in particular in the temperature changes north of Scandinavia, where the presence of sea-ice suggests that the response would not scale linearly, and in the zonal wind over the western North Atlantic.

To illustrate the scatter in the relationship, Figure 2a compares the MOC response with the storm track response averaged over the main storm track region, where there is also a strong and significant relation with the MOC response in Figure 1. There is one outlying model with a very strong MOC decrease, but regardless of whether or not this model is included in the analysis the regression accounts for at least half of the spread in the storm track responses between the models. Figure 2a also shows that the storm track responses are generally as large as the internal decadal variability, and that for models with a strong MOC response the storm track response is large enough to be of the same magnitude as the interannual variability. In fact for some of the individual models this signal-tonoise ratio is close to or greater than one (not shown). The MOC therefore appears to be a strong source of uncertainty in climate projections of Atlantic storm track change.

This regression analysis can also be used to infer the role of the MOC reduction in the ensemble mean storm track response to forcing. Figure $2 \mathrm{~b}$ shows the diagnosed ensemble mean storm track response and Figure 2c shows an estimate of the same quantity, calculated by applying the pointwise regression fits of Figure 1c to 
the ensemble mean MOC response. The MOC-derived estimate is very similar in character to the diagnosed response, and the residual pattern (Figure 2d) shows that they differ only in a southward shift of the storm track which is evident in the diagnosed response but not in the MOC-derived estimate.

Atmospheric changes such as the storm track and zonal wind responses seen here are likely to influence the ocean circulation in various ways ${ }^{24 ; 25}$. To show that the ocean is not simply responding to the atmospheric changes we now analyse the slab model versions contained in the CMIP3 archive. These models do not represent changes in ocean dynamics and heat transports (see methods), so differences in the ensemble mean responses of slab models and AOGCMs indicate that the AOGCM mean response is influenced by the ocean. The pronounced minimum in surface warming in the North Atlantic in the AOGCMs (Figure 3a) is not seen in the corresponding slab models (Figure 3d, with the difference field in Figure 3g). This confirms that this feature arises due to the changes in ocean circulation and heat transport, which is generally assumed but has not been demonstrated before in this way to our knowledge. However, the zonal wind responses are almost identical in the slab models and AOGCMs (Figure 3b, e, h). This suggests that changing ocean heat transport has little influence on this part of the mean zonal wind response of the AOGCMs.

In contrast, the storm track response is different in the AOGCMs and slab models (Figure 3c, f, i). Interestingly, the response in the slab models is a strengthening of the storm track, so that even in the absence of ocean circulation changes the North Atlantic storm track does not shift poleward in response to forcing. The addition of a dynamic coupled ocean then acts to shift the storm track southward in the response pattern. This is consistent with the enhanced meridional SST gradient at latitudes south of the British Isles, corresponding to an increase in baroclinic instability for storm development, and a decreased meridional gradient 
at latitudes to the north. The slab model comparison therefore confirms that the changes in ocean circulation have some impact on the storm track. Surprisingly, the storm track and low-level zonal wind responses appear to be decoupled to some extent in the model responses. This is a general feature of the mean response of the AOGCMs, where the zonal winds shift to the north and storm track shifts to the south. Further investigation is clearly required on the relation between the storm track, the eddy-driven jet and the baroclinic zone in a changing climate.

The results presented here show that there is a strong relation between the MOC and storm track responses in the AOGCMs. The response of the atmospheric mean circulation and storm tracks will influence both gyre and overturning circulations through changes in wind stress forcing and surface fluxes. Analysis of the slab model versions shows that the changes in ocean circulation in turn influence the storm track response, and comparison with the hosing simulation provides further evidence of causality from the MOC in particular. In this way the ocean and atmosphere circulations are responding to the forcing as a coupled system.

There is an interesting contrast between the slab model and AOGCM results. Figure 2 shows that the aspect of the mean storm track change which cannot be explained as a linear response to the mean MOC change is the particular strengthening of the storm track on its southern flank. Correspondingly, the mean effect of including a dynamical ocean model is precisely to shift the storm track south in the response pattern (Figure 3). These storm track differences are consistent with the differences in SST patterns, which are focused in the western North Atlantic in Figure 1a but extend across the basin in Figure 3g. This implies that the MOC alone is not sufficient to explain all of the coupling introduced with a dynamical ocean model, and other processes such as changes in the wind-driven circulation may play a role $26 ; 27$. 
180

This paper shows that future storm track uncertainty could be reduced if projections of MOC behaviour can be better constrained, either through improvements in climate modelling or ocean observation. For example, climate models with a relatively strong MOC in their control simulations tend to predict a larger than average reduction in the MOC. The correlation between these quantities is 0.46 for the models in Figure 2 but has been found to be larger in other model ensembles $^{21 ; 28}$. Observational estimates of MOC strength could therefore provide an effective means of constraining future storm track projections.

\section{Methods}

In this paper we analyse the ensemble of climate model simulations performed for the third Coupled Model Intercomparison Project (CMIP3). Up to 22 coupled amosphere-ocean general circulation models (AOGCMs) have been used, depending on the data availability for the specific diagnostics required, and these are described in the Fourth Assessment Report of the Intergovernmental Panel on Climate Change ${ }^{29}$. The forcing scenarios 20C3M and SRESA1B are used to characterise the end of the 20th and 21st centuries respectively.

Following previous work ${ }^{8}$, the storm track is described using the standard deviation of 2-6 day bandpass filtered sea level pressure (SLP; hPa), for which the necessary data is available for many of the models for the periods 1960-99 and 208099. Monthly mean fields of surface air temperature $(\mathrm{K})$ and zonal wind $\left(\mathrm{m} \mathrm{s}^{-1}\right)$ have also been used, in this case over the longer 21st century period of 2060-99 since the data is available. The surface air temperature describes changes in seaice as well as SST, which may play a role in the ocean-atmosphere interaction. In all cases, the response to anthropogenic forcing is defined as the DJF mean of the future period minus the DJF mean of the control period. The MOC is described 
by the maximum value of the meridional streamfunction $\left(\mathrm{Sv} \equiv 10^{6} \mathrm{~m}^{3} \mathrm{~s}^{-1}\right)$ at $45 \mathrm{~N}$ in the Atlantic Ocean, although similar results are obtained if the MOC is instead defined by the maximum value wherever it occurs. All results are derived using wintertime (DJF) atmospheric data but annual mean MOC values.

Figure 2a includes values of the models' internal variability in the period 196099. For each model the interannual variability was calculated as the standard deviation of the individual winter means and the boxplot summarises these 14 values. For the decadal variability one value was obtained by combining the decadal means from all 14 models (after removal of each model's climatology) and taking the standard deviation of this set of 56 decadal anomalies.

The slab models used comprise an atmospheric model, as in an AOGCM, coupled to a single-layer ocean model, with prescribed seasonally varying fields of ocean heat convergence $\left(\mathrm{W} \mathrm{m}^{-2}\right)$, which takes the place of a dynamically evolving ocean. Comparison of the AOGCM and slab model responses reveals the importance of changes in ocean heat transports in shaping the storm track responses. The slab simulations are equilibrium experiments with pre-industrial (year 1860, with 280 ppm CO2) and doubled carbon dioxide concentrations.

The HadCM3 hosing simulations were performed by Vellinga and $\mathrm{Wu}^{23}$ and we analyse the same twenty year periods as in Brayshaw et al. ${ }^{13}$. Between these two periods the maximum MOC at $45 \mathrm{~N}$ in the Atlantic decreases from 21.6Sv to 0.9Sv.

Correspondence and requests for materials should be addressed to T. Woollings (t.j.woollings@reading.ac.uk).

\section{Author Contributions}

TW led the analysis and writing of the paper, JMG analysed the ocean data, JGP and MR analysed the storm track data and DJB analysed the HadCM3 data. All 
authors contributed to writing the paper.

\section{Acknowledgments}

We acknowledge the modeling groups, the Program for Climate Model Diagnosis and Intercomparison (PCMDI) and the WCRP's Working Group on Coupled Modelling (WGCM) for their roles in making available the WCRP CMIP3 multimodel dataset. Support of this dataset is provided by the Office of Science, U.S. Department of Energy. We would like to thank Julia Moemken (Univ. Cologne) for assistance with some of the data processing, Michael Vellinga (UK Met Office) for providing data from the HadCM3 hosing simulations and the reviewers for their constructive and helpful comments.

\section{References}

[1] G. A. Meehl et al. Global climate projections. In S. Soloman et al., editors, Climate change 200\%: The physical science basis, chapter 10. Cambridge University Press, 2007.

[2] J. H. Yin. A consistent poleward shift of the storm tracks in simulations of 21st century climate. Geophys. Res. Lett., 32(L18701), 2005. doi:10.1029/2005GL023684.

[3] D. J. Lorenz and E. T. DeWeaver. Tropopause height and zonal wind response to global warming in the IPCC scenario integrations. J. Geophys. Res., 112:D10119, 2007.

[4] G. Chen, J. Lu, and D. M. W. Frierson. Phase Speed Spectra and the Latitude 
of Surface Westerlies: Interannual Variability and Global Warming Trend. J. Climate, 21:5942-5959, 2008.

[5] P. A. O'Gorman. Understanding the varied response of the extratropical storm tracks to climate change. P Natl. Acad. Sci. USA, 1071:19176-19180, 2010.

[6] G. Riviere. A Dynamical Interpretation of the Poleward Shift of the Jet Streams in Global Warming Scenarios. J. Atmos. Sci., 68:1253-1272, 2011.

[7] J. Kidston, G. K. Vallis, S. M. Dean, and J. A. Renwick. Can the Increase in the Eddy Length Scale under Global Warming Cause the Poleward Shift of the Jet Streams? J. Climate, 24:3764-3780, 2011.

[8] U. Ulbrich, J. G. Pinto, H. Kupfer, G. C. Leckebusch, T. Spangehl, and M. Reyers. Changing Northern Hemisphere Storm Tracks in an Ensemble of IPCC Climate Change Simulations. J. Climate, 21:1669-1679, 2008.

[9] J. G. Pinto, U. Ulbrich, G. C. Leckebusch, T. Spangehl, M. Reyers, and S. Zacharias. Changes in storm track and cyclone activity in three SRES ensemble experiments with the ECHAM5/MPI-OM1 GCM. Climate Dynam., 29:195-210, 2007.

[10] J. G. Pinto, E. L. Fröhlich, G. C. Leckebusch, and U. Ulbrich. Changing European storm loss potentials under modified climate conditions according to ensemble simulations of the ECHAM5/MPI-OM1 GCM. Natural Hazards and Earth System Sciences, 7:165-175, 2007.

[11] C. Schwierz, P. Koellner-Heck, E. Zenklusen Mutter, D. N. Bresch, P.-L. Vidale, M. Wild, and C. Schaer. Modelling European winter wind storm losses in current and future climate. Clim. Change, 101:485-514, 2010. 
[12] P. Dailey, M. Huddleston, S. Brown, and D. Fasking. The financial risks of climate change. Technical report, AIR Worldwide Corp and the UK Met Office, 2009. Association of British Insurers Research Paper 19.

[13] D. J. Brayshaw, T. Woollings, and M. Vellinga. Tropical and Extratropical Responses of the North Atlantic Atmospheric Circulation to a Sustained Weakening of the MOC. J. Climate, 22:3146-3155, 2009.

[14] D. J. Brayshaw, B. Hoskins, and M. Blackburn. The basic ingredients of the North Atlantic storm track. Part II: Sea surface temperatures. J. Atmos. Sci., 68:17841805, 2011.

[15] C. Wilson, B. Sinha, and R. Williams. The effect of ocean dynamics and orography on atmospheric storm tracks. J. Climate, 22:3689-3702, 2009.

[16] L. Shaffrey and R. Sutton. Bjerknes compensation and the decadal variability of the energy transports in a coupled climate model. J. Climate, 19:1167-1181, 2006.

[17] L. Bengtsson, K. I. Hodges, and E. Roeckner. Storm tracks and climate change. J. Climate, 19:3518-3543, 2006.

[18] A. Laîné, M. Kageyama, D. Salas-Mélia, G. Ramstein, S. Planton, S. Denvil, and S. Tyteca. An Energetics Study of Wintertime Northern Hemisphere Storm Tracks under 4 x CO2 Conditions in Two Ocean-Atmosphere Coupled Models. J. Climate, 22:819-839, 2009.

[19] J. L. Catto, L. C. Shaffrey, and K. I. Hodges. Northern Hemisphere extratropical cyclones in a warming climate in the HiGEM High Resolution Climate Model. J. Climate, 24:5336-5352, doi:10.1175/2011JCLI4181.1, 2011. 
[20] R. E. McDonald. Understanding the impact of climate change on Northern Hemisphere extra-tropical cyclones. Climate Dynam., 37:1399-1425, 2011, doi:10.10007/s00382-010-0916-x, 2011.

[21] J. M. Gregory et al. A model intercomparison of changes in the Atlantic thermohaline circulation in response to increasing atmospheric $\mathrm{CO} 2$ concentration. Geophys. Res. Lett., 32:L12703, 2005.

[22] R. J. Stouffer, J. Yin, J. M. Gregory, K. W. Dixon, M. J. Spelman, W. Hurlin, A. J. Weaver, M. Eby, G. M. Flato, H. Hasumi, A. Hu, J. H. Jungclaus, I. V. Kamenkovich, A. Levermann, M. Montoya, S. Murakami, S. Nawrath, A. Oka, W. R. Peltier, D. Y. Robitaille, A. Sokolov, G. Vettoretti, and S. L. Weber. Investigating the Causes of the Response of the Thermohaline Circulation to Past and Future Climate Changes. J. Climate, 19:1365-1387, 2006.

[23] M. Vellinga and P. Wu. Relations between Northward Ocean and Atmosphere Energy Transports in a Coupled Climate Model. J. Climate, 21:561, 2008.

[24] J. Marshall, H. Johnson, and J. Goodman. A study of the interaction of the North Atlantic Oscillation with ocean circulation. J. Climate, 14:1399-1421, 2001.

[25] H. Hátún, A. B. Sandø, H. Drange, B. Hansen, and H. Valdimarsson. Influence of the Atlantic Subpolar Gyre on the Thermohaline Circulation. Science, 309:1841-1844, 2005.

[26] C. C. Raible and R. Blender. Northern Hemisphere midlatitude cyclone variability in GCM simulations with different ocean representations. Climate Dynam., 22:239-248, 2004. 
317 [27] W. Park and M. Latif. Ocean Dynamics and the Nature of Air-Sea Interactions

318

319

320

321

322

323

324 over the North Atlantic at Decadal Time Scales. J. Climate, 18:982-995, 2005.

[28] J. M. Gregory and R. Tailleux. Kinetic energy analysis of the response of the Atlantic meridional overturning circulation to $\mathrm{CO}_{2}$-forced climate change. Clim. Dyn., 37:893-914, 2011.

[29] D. A. Randall et al. Climate models and their evaluation. In S. Soloman et al., editors, Climate change 200\%: The physical science basis, chapter 8 . Cambridge University Press, 2007. 
a) TAS regressed on $\triangle M O C$

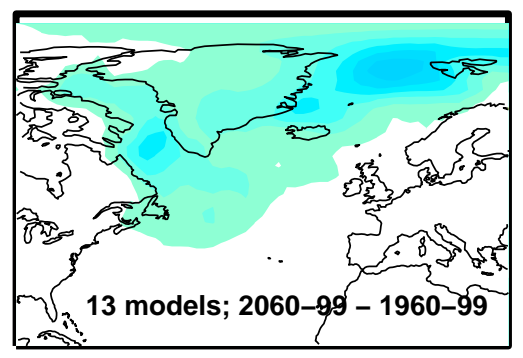

d) TAS EOF 1: $46 \%$ of var

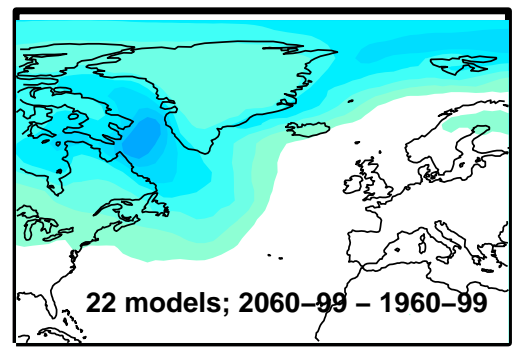

g) Surface temp. response to hosing

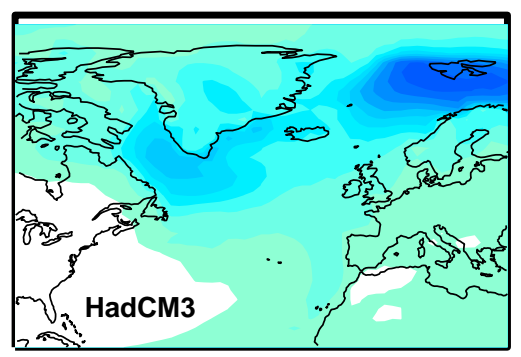

Temperature (K)

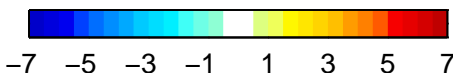

b) U850 regressed on $\triangle$ MOC

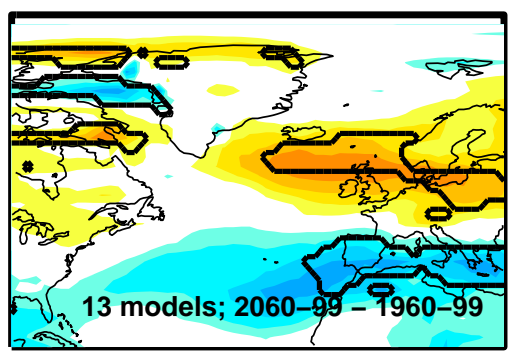

e) U850 regressed on TAS EOF1

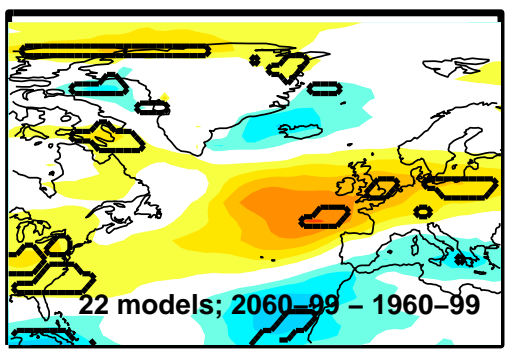

h) U850 response to hosing

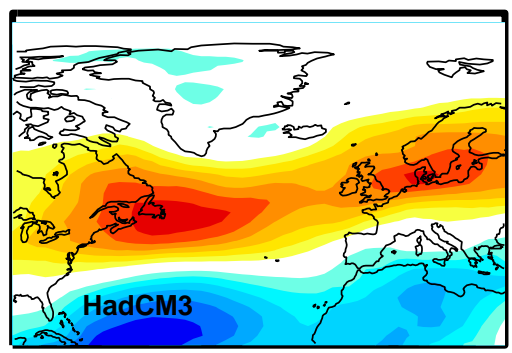

$850 \mathrm{hPa}$ zonal wind $(\mathrm{m} / \mathrm{s})$

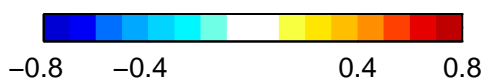

c) Storm track regressed on $\triangle$ MOC

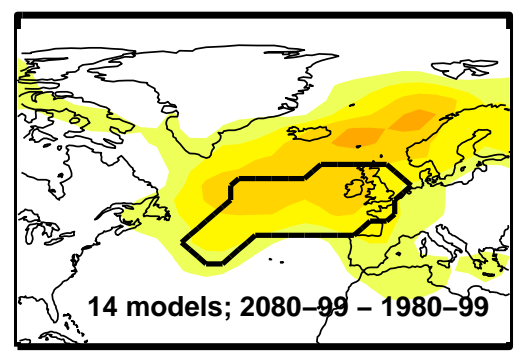

f) Storm track regressed on TAS EOF 1

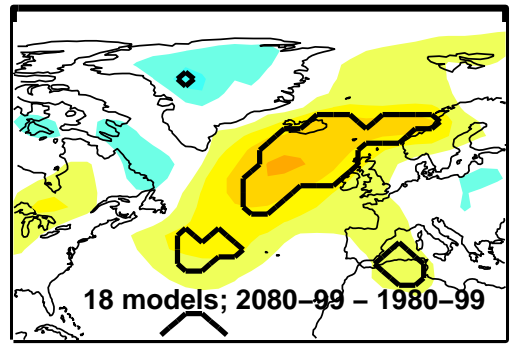

i) Storm track response to hosing

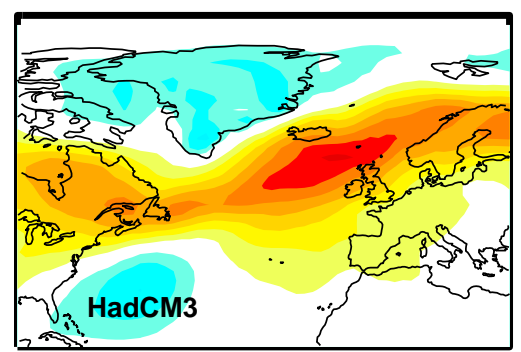

Storm track $(1 / 10 \mathrm{hPa})$

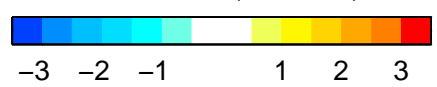

Figure 1: Maps of regression slopes quantifying ocean-atmosphere relationships in the wintertime responses of the AOGCMs to anthropogenic forcing. In each panel, at each point, a linear regression is done across the set of models. Panels a-c show the responses in surface temperature (TAS), $850 \mathrm{hPa}$ zonal wind (U850) and storm tracks (standard deviation of 2-6 day filtered SLP) regressed onto the MOC reduction in the models. Panels d-f show the same quantities regressed onto the leading EOF of the surface temperature response. In each case the regressions are performed over the longest period and largest set of models permitted by the data availability, as indicated. The independent variable in each case has been normalised so that each panel shows the pattern associated with one standard deviation of the spread between the models. Black contours in the zonal wind and storm track panels show regions where the patterns are inconsistent with random sampling at the $95 \%$ level, as estimated using a Monte Carlo shuffling of the models. Panels g-i show the responses in the same fields in the HadCM3 freshwater hosing experiment for comparison. 
a) MOC / Storm track scatter: 2081-2100 (A1B) - 1961-2000 (20C3M)

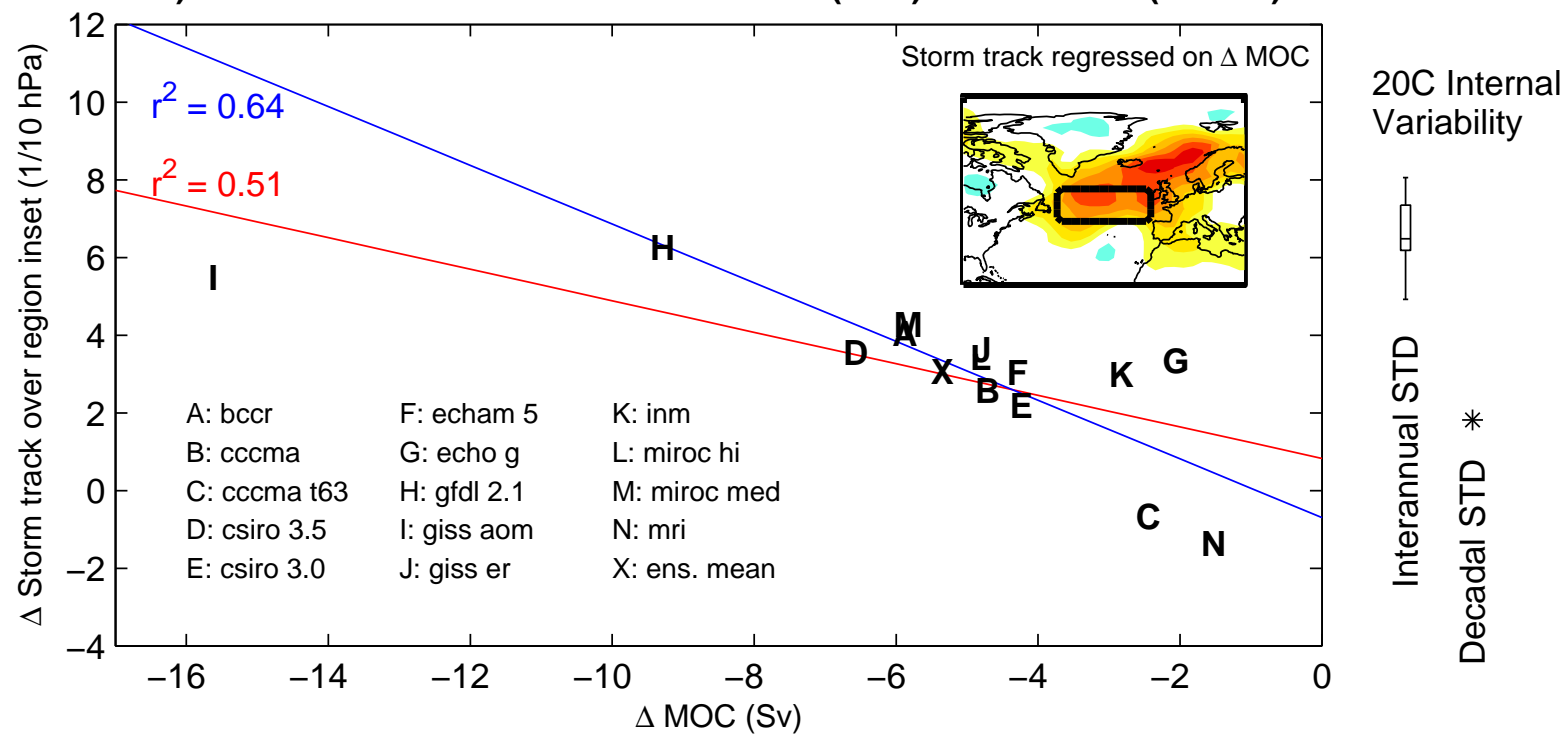

b) Full response

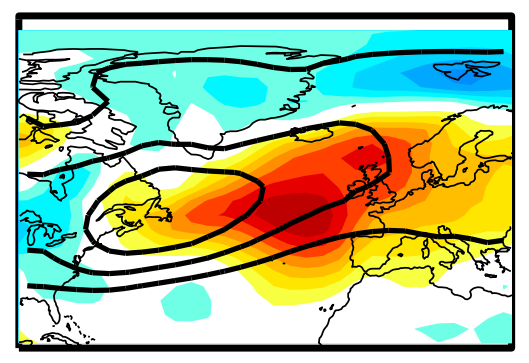

c) MOC regression

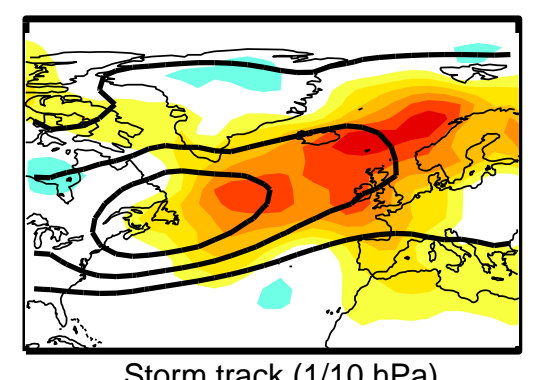

Storm track $(1 / 10 \mathrm{hPa})$

d) Residual
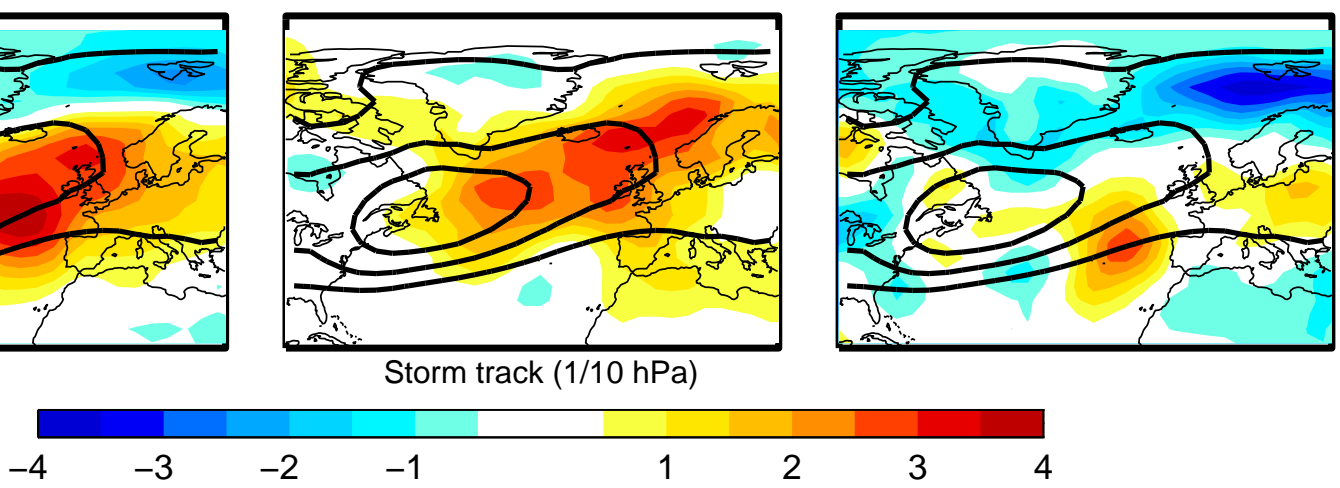

Figure 2: Quantifying the role of the MOC in the mean and model spread of the storm track response. a) Scatterplot of the storm track response area-averaged over the region shown inset $\left(45-55^{\circ} \mathrm{N}, 10-50^{\circ} \mathrm{W}\right)$ against the MOC response in the AOGCMs. Regression lines are shown both including (red) and excluding (blue) the outlier model I. For comparison, the magnitude of internal variability of the same region in the control ensemble is summarised with respect to the same y axis (see methods). b) The ensemble mean diagnosed storm track response of this subset of 14 models. c) The response estimated using the ensemble mean MOC response. d) The residual b-c. Contour lines in b-d show the storm track in the control ensemble at 3, 4 and $5 \mathrm{hPa}$. 
a) TAS: AOGCMs

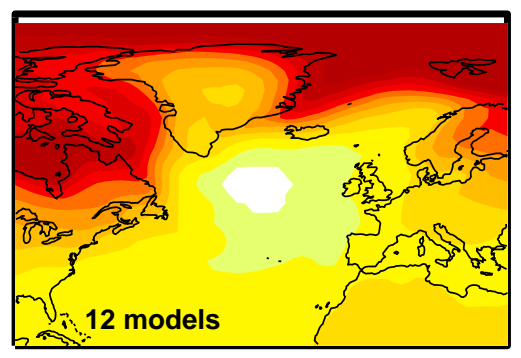

d) TAS: Slab models

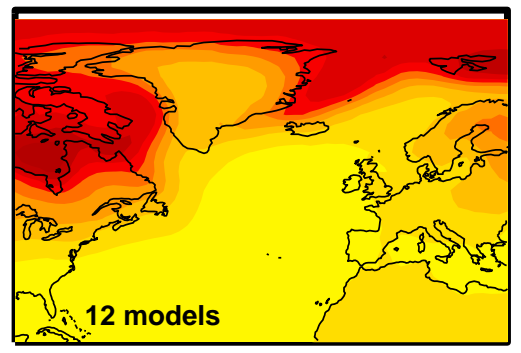

g) TAS: AOGCM - slab

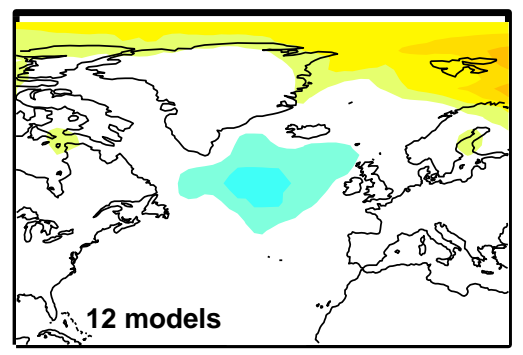

Temperature (K)

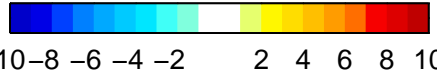

b) U850: AOGCMs

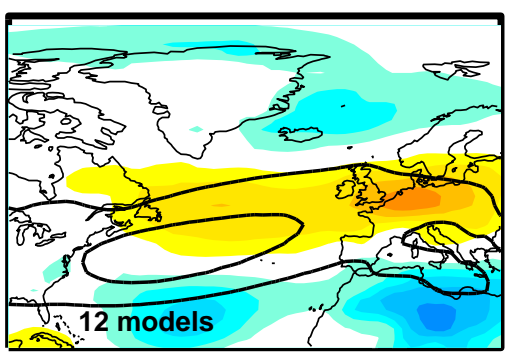

e) U850: Slab models

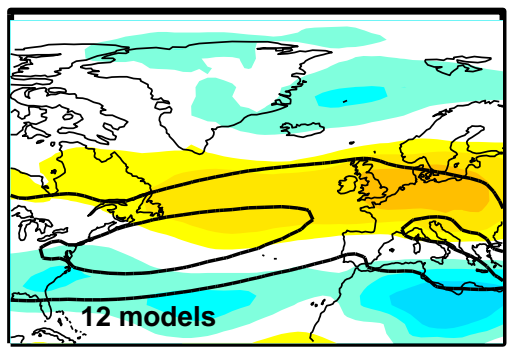

h) U850: AOGCM - slab

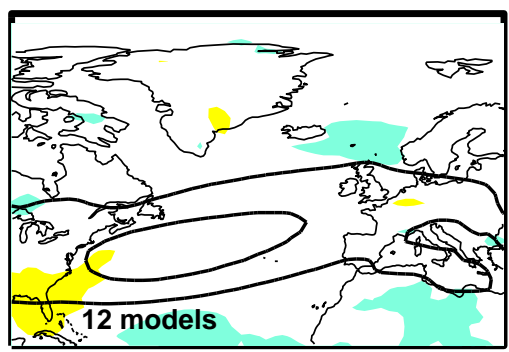

$850 \mathrm{hPa}$ zonal wind $(\mathrm{m} / \mathrm{s})$

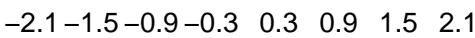

c) Storm track: AOGCMs

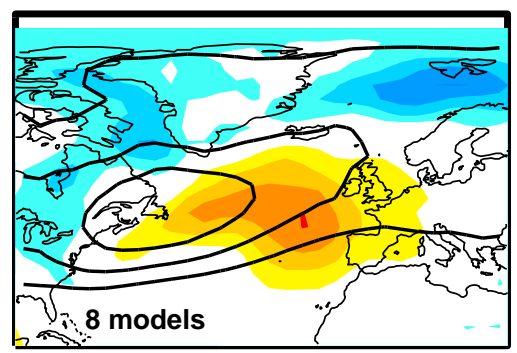

f) Storm track: Slab models

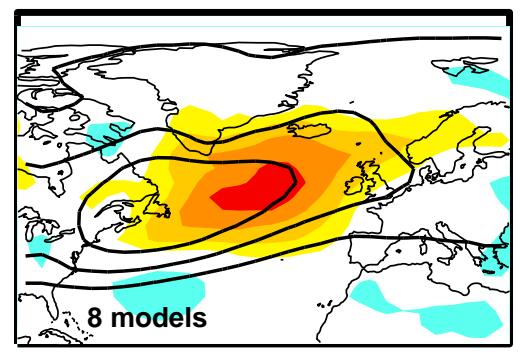

i) Storm track: AOGCM - slab

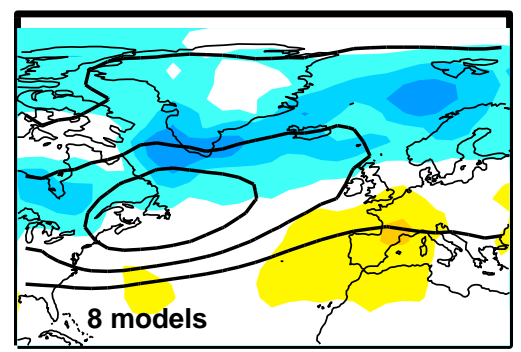

Storm track $(1 / 10 \mathrm{hPa})$

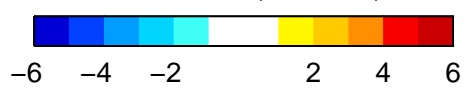

Figure 3: Comparison of the mean responses of the surface temperature (TAS), $850 \mathrm{hPa}$ zonal wind (U850) and the storm tracks in the AOGCMs and slab models. In all cases the responses have been scaled by the global mean surface temperature response so that the magnitude of warming is comparable despite the differences among models in forcing, transient climate response and equilibrium climate sensitivity. Solid contours mark control period ensemble mean values (5 and $10 \mathrm{~m} \mathrm{~s}^{-1}$ for the zonal winds and 3,4 and $5 \mathrm{hPa}$ for the storm tracks). 